\title{
Prenatal diagnosis: A cytogenetic approach
}

\author{
Suchitra Kumari \\ Associate Professor, Dept. of Biochemistry, All India Institute of Medical Sciences, Bhubaneswar, Odisha, India
}

*Corresponding Author:

Received: $16^{\text {th }}$ October, 2017

Email: suchitrakumari76@gmail.com

\begin{abstract}
Prenatal diagnosis is offered to patients at risk of chromosome anomalies with Abnormal ultrasound scan, Carrier of a chromosomal structural rearrangement and Elevated risk of aneuploidy indicated by biochemical and/or ultrasound screening. It is usually carried out using samples like Amniotic fluid (AF), Chorionic Villus Samples (CVS) or Foetal blood. Prenatal diagnosis involves both invasive and non -invasive techniques. Non-invasive tests are getting acceptance by the patients \& obstetricians worldwide but still they are used as screening tool not as diagnostic measure. Genetic diagnosis guide in making decisions about maintaining or ending a pregnancy. So many ethical issues must be considered before screening or testing pregnancies for underlying genetic disorders. There must be compliance with legal requirements and constraints applicable to the communication of confidential information.
\end{abstract}

Keywords: Chromosome anomalies, Prenatal diagnosis, aneuploidy, Foetal blood.

\section{Introduction}

Prenatal Diagnosis started in the fifties with prenatal sex determination in amniotic Fluid cells. In 1966, Steele and Breg showed that chromosome constitution of fetus could be determined by amniotic fluid cultured cells analysis. ${ }^{1}$ The first attempt of $1^{\text {st }}$ Trimester prenatal diagnosis were made by Kullender and Sandahl (1973) and Hahneman (1974) who used long term cultures of Chorionic villi from $1^{\text {st }}$ trimester abortions for foetal karyotyping. ${ }^{2}$ In 1975, Chinese group (Anshen Iron \& steel Company) reported foetal sex chromatin analysis in direct preparations of Chorionic villi during early pregnancy ${ }^{3}$. Screening of the pregnant ladies for genetic disorders like Down syndrome, Neural Tube defects, Thalassemia major, etc. are the milestones in Prenatal Diagnosis.

Indications for invasive Prenatal Diagnosis ${ }^{4}$ include:

1. Maternal age of 35 years at the expected date of confinement(Advanced maternal age ).

2. History of previous child with de novo chromosomal aneuploidy i.e. Down syndrome.

3. One of the parents having structural chromosomal abnormalities.

4. Family history of $x$-linked disorder i.e. Duchenne Muscular Dystrophy, Haemophilia A and B.

5. Risk of a neural tube defect and abnormal findings in maternal serum screening and ultrasound examination.

\section{Methods of Prenatal Diagnosis and Screening:}

Invasive Techniques:

a. Amniocentesis

b. Chorionic Villus Sampling

c. Cordocentesis d. Pre-implantation genetic diagnosis (PGD)

Non-invasive Techniques:

a. Maternal serum alpha-feta protein

b. First and second trimester maternal serum screening

c. Isolation of fatal cells in maternal circulation

d. Ultrasonography

The American college of Medical genetics and Genomics and the International Society of Prenatal Diagnosis have issued guidelines about use of aneuploidy tests on free fetal DNA in maternal blood as a screening test. The non-invasive tests are getting acceptance by the patients \& obstetricians worldwide but these tests are used as screening tool not as diagnostic test ${ }^{5}$. All screen-positive pregnant ladies should undergo confirmatory test by amniocentesis.

\section{Screening for Down syndrome}

First trimester screening: Performed ideally between 11-13 weeks of gestation. Maternal serum PregnancyAssociated Plasma Protein A (PAPP-A), Human Chorionic Gonadotropin ( $\beta$-hCG) are the investigations carried out in first trimester of pregnancy. PAPP-A is depressed below the normal range in all trisomies, $\beta$ hCG is elevated in trisomy 21 but depressed in other trisomies ${ }^{6}$. Ultrasonography revealed increased nuchal translucency in the first trimester of pregnancy.

\section{Second trimester screening}

Triple screen: Include estimating 3 substances in the mother's serum i.e. MSAFP (Maternal serum Alfa fetoprotein), free $\beta$-hCG and unconjugated estriol. ${ }^{7}$

Quadruple Screen: All these substances are depressed below the normal range in all trisomies with the exception of free $\beta$-hCG which is elevated in trisomy 21 but depressed in the other trisomies .Studies 
suggested that mostly Inhibin A is elevated in trisomy 21 but not significantly affected in the other trisomies. Second trimester triple and quadruple screens provide detection rates for autosomal trisomies of approx. $72 \%$ and $81 \%$ respectively. ${ }^{9}$

Preimplantation genetic diagnosis (PGD): Preimplantation genetic diagnosis (PGD) has come up in the field of prenatal diagnosis for approximately a decade. Parents with family histories of serious monogenic disorders and translocations are the ones who frequently undergo these tests.

Two widely used methods of PGD are:

1. Polar body testing

2. Blastomere testing

Polar Body Testing: Polar bodies are tested to analyse the genetic status of the oocyte. So only the maternal genetic contribution can be studied not the paternal derived disorders. Polar body testing involving 2 polar bodies increase the accuracy and efficiency of diagnosis because of recombination events.

Blastomere PGD: This process involves removal of one or two blastomere cells from the 4-8 cell preembryo stage, for the purpose of pre-implantation analysis. Subsequent genetic analysis is carried out after removal of the cell(s) from the blastomere, placing the developing embryo into the culture dish and inserting the removed cell(s) into a test tube.

Chromosomal Analysis: Either amniocentesis or CVS can provide fatal cells for karyotyping as well as for biochemical or DNA analysis. Preparation and analysis of chromosome from cultured amniotic fluid cells or cultured chorionic villi require 7-10 days. Fluorescence in situ hybridization is used to screen interphase nuclei in fetal cells for aneuploidies of chromosome 13, 18, $21, \mathrm{X}$ and $\mathrm{Y} .{ }^{10}$ However, a larger number of cells may be analysed to investigate the presence of Mosaicism (presence of 2 or more cell lines in an individual or tissue sample).

Karyotype Analysis: The 24 types of chromosome can be identified by the unique banding pattern exhibited with various stains. There are three commonly used staining methods. The most common method used in clinical laboratories of karyotype analysis is Giemsa (G) banding, others are Quinacrine Mustard (Q Banding) and $\mathrm{R}$ banding (chromosome receives special treatment i.e. heating before staining. ${ }^{11}$

Fluorescence in situ Hybridization (FISH): FISH is mainly used to examine the presence or absence of particular DNA sequence or to evaluate the organization of a chromosome or chromosomal region. It detects the presence or absence of micro deletions, micro duplications and aneuploidy. ${ }^{12}$ DNA probes (specific for chromosome, chromosomal region or genes)can be used to detect the presence, absence or location of a particular gene both in metaphase as well as interphase cells; treated with antibodies, finally, the fluorescent signals are examined under the microscope (Fig. 1).
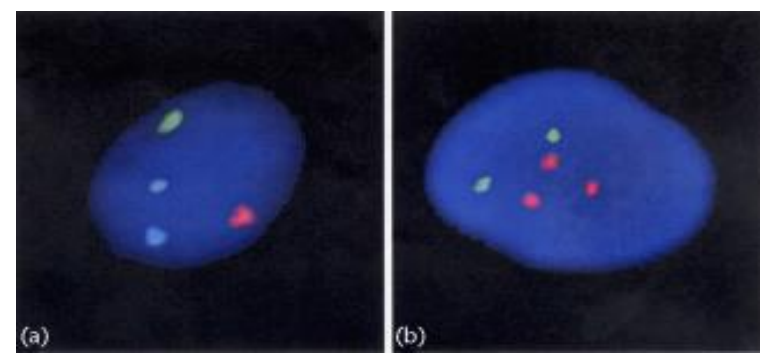

Fig. 1: An example of fluorescence in situ hybridization (FISH) analysis, wherein interphase nuclei from an amniocentesis sample are hybridized with probes for chromosomes 13, 18, 21, $\mathrm{X}$ and $\mathrm{Y}$. (a) A nucleus has been hybridized with probes for chromosomes 18 (aqua), X (green) and one Y (red). (b) A nucleus has been hybridized with probes for chromosomes 13 (green) and 21 (red)

\section{DNA Molecular Analysis}

Once a specimen is collected, a variety of laboratory techniques may be used to diagnose single gene disorders prenatally. ${ }^{13}$ Choosing which technique to use depends upon the suspected disorder.

\section{Direct DNA analysis}

Direct mutation analysis involves analysing a target segment of DNA for the presence of a specific mutation. DNA analysis can be performed either by direct mutation screening or indirect approach of genetic linkage analysis by using markers. ${ }^{14}$

\section{Mutation analysis with restriction enzymes}

In the mutations known to alter the splice site, direct analysis by restriction enzyme assay will is be useful in identifying the polymorphism. Single restriction enzyme ${ }^{15}$ (known to cut the DNA at a specific splice site) is used to digest the Control as well as the Sample DNA, the resultant DNA fragments (called restriction fragment length polymorphisms, or RFLPs) are analysed to detect the presence of a mutation by Southern blotting (Fig. 2). 

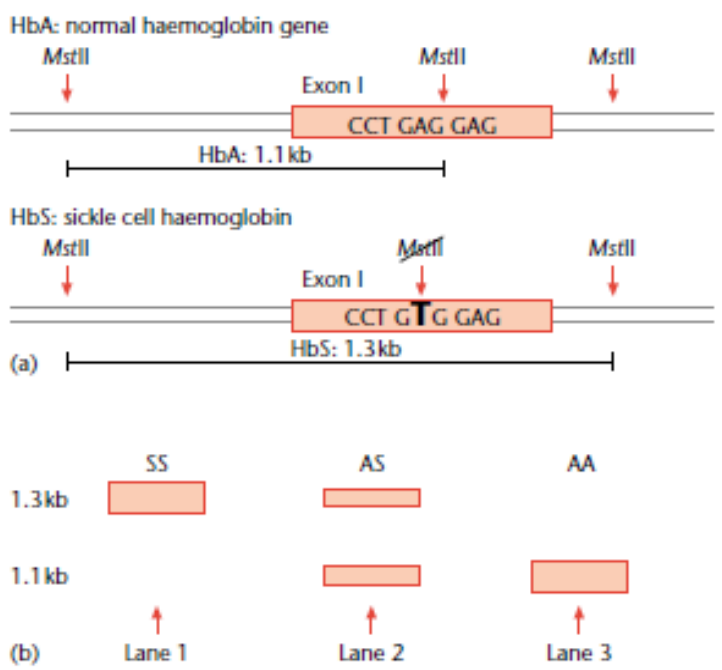

Fig. 2: Direct mutation analysis with restriction enzymes. (a) Sickle cell anaemia and $\beta$ haemoglobin gene (b) Southern blot analysis

\section{Sequencing of restriction enzyme products}

The DNA fragments obtained by restriction digestion, can be sequenced by Sanger dideoxy method, a specialized amplification technique (Fig. 3).

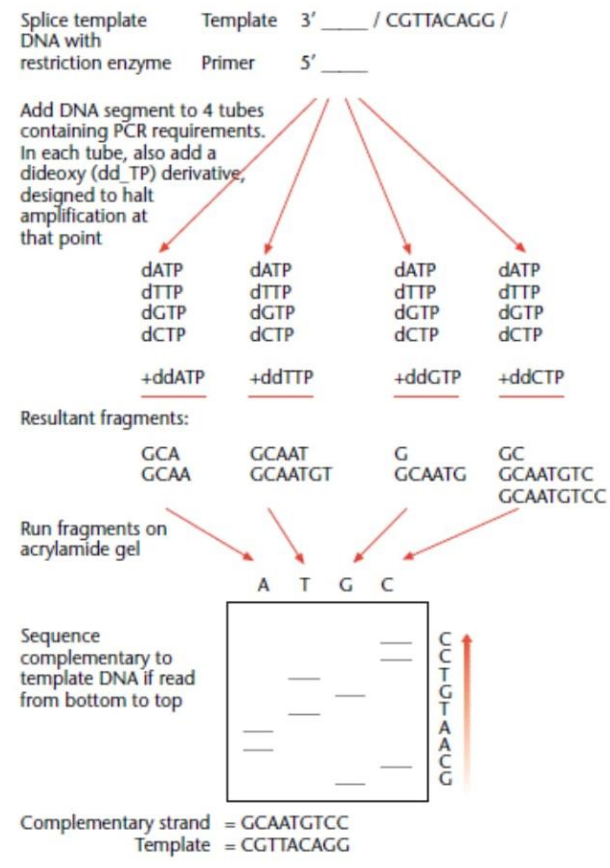

Fig. 3: Sanger dideoxy method (Sequencing restriction enzymes and polymerase chain reaction)

Linkage Analysis: Linkage analysis is a method of mapping genes that use family studies to detect linkage between two genes passes on from one generation to other. This is an indirect means of detecting a patient's mutation status. Microsatellite repeats, Restriction Fragment Length Polymorphisms (RFLPs) and Variable Number Tandem Repeats (VNTRs) are used as marker of Polymorphism. DNA from affected and healthy unaffected family members is analysed for these polymorphisms to determine the mutation pattern 16 .

\section{New Diagnostic Techniques}

Fetal cells in maternal circulation: Some cells from the developing fetus may enter into the maternal circulation in early stage of first trimester of pregnancy. Isolation and genetic analysis of such cells is one of the recent cell-based non-invasive prenatal diagnostic tests. Fetal cells isolated from maternal blood (based on the markers they express on their surface), identified by staining, separated from maternal cells for chromosome and/or DNA analysis. ${ }^{17}$

\section{Ethics}

Prenatal diagnosis is used to guide the couple to avoid having offspring with a serious hereditary disorder. So, it is important to consider the ethics, of the given situation. Genetic diagnosis help in making a decision about maintaining or ending a pregnancy, place stress upon the family. The ethical issues ${ }^{18}$ include:

1. The ethical dilemmas to continue or abort a pregnancy.

2. Prenatal testing seldom leads to treatment beneficial to the fetus. Is knowledge of the test result more beneficial than harmful or vice versa?

3. Are the risks of invasive prenatal diagnostic procedures, such as amniocentesis worth the potential benefit?

4. Questions of privacy of genetic information and Duty to warn family members.

\section{Conclusion}

Prenatal diagnosis opens the door to a new era of genetics in Medicine, knowledge that improve health, relieving suffering. Ethical principles are intertwined with prenatal genetic testing, so each case requires integrated team approach to ensure most appropriate care.

\section{References}

1. Abruzzo MA and Hassold TJ (1995) .The aetiology of non disjunction in humans. Environmental and Molecular Mutagenesis 25 (supplement 2):38-47.

2. Eddleman KA ,Malone FD, Sullivan L et al. Pregnancy loss rates after mid trimester amniocentesis. Obstet Gynecol 2006;108:1067-72.

3. Ferguson-Smith and Yates RW. Maternal age specific rates for chromosome aberrations and factors influencing them: report of a collaborative European study on 52965 amniocenteses. Prenatal Diagnosis 1984:4 (Spec. No.):544.

4. Fan HC, Blumenfeld YJ, Chitkara U, Hudgins L, Quake SR (October 2008). Noninvasive diagnosis of fetal aneuploidy by shotgun sequencing DNA from maternal blood. Proc. Natl. Acad. Sci. U.S.A. 105 (42):16266-71. 
5. Gjerris, A. C.; Tabor, A.; Loft, A.; Christiansen, M.; Pinborg, A. (2012). "First trimester prenatal screening among women pregnant after IVF/ICSI". Human Reproduction Update 18 (4):350-9.

6. Reddy UM, Mennutti MT. Incorporating first trimester Down's Syndrome studies into prenatal screening. Obstet Gynecol2006;107:167-73.

7. Ball RH, Caughey AB, Malone FD, et al. First- and second-trimester evaluation of risk for Down syndrome. Obstet Gynecol 2007;110 (1):10-7.

2. 8.Professional Guidelines for Clinical Cytogenetics: General Best Practice Guidelines (2007); www.cytogenetics.org.uk.

1. Lao, M.R.; Calhoun, B. C.; Bracero, L. A.; Wang, Y.; Seybold, D. J.; Broce, M.; Hatjis, C. G. The ability of the Quadruple test to predict adverse perinatal outcomes in a high risk obstetric population.J Med Screen 2009;16 (2):55-9.

3. 10.. Harper JC, Delhanty JDA and Handyside AH (2000). Preimplantation Genetic Diagnosis. Chichester: Wiley. [A guide to preimplantation diagnosis.]

4. 11. Miny, P; Tercanli S, Holzgreve W (April 2002). "Developments in laboratory techniques for prenatal diagnosis". Current Opinion in Obstetrics and Gynecology 14(2):161-8.

5. 12. Papageorgiou EA, Karagrigoriou A, Tsaliki E, Velissariou V, Carter NP, Patsalis PC (April 2011) "Fetal-specific DNA methylation ratio permits non invasive prenatal diagnosis of trisomy $21 "$. Nat. Med.17(4):510-13.

6. 13. Yong PJ, Marion SA et al .Evidence for imprinting on chromosome 16; the effect of uniparental disomy on the outcome of mosaic trisomy 16 pregnancies Am JMed Genet 2012;112:123-32.

7. 14. Yong PJ, Barrett IJ et al . Clinical aspects, prenatal diagnosis and pathogenesis of trisomy 16 mosaicism J Med Genet 2012;40:175-82.

8. 15.Jurg Ott, Jing Wang \& Suzanne M Leal. Genetic linkage analysis in the age of whole-genome sequencingNature Reviews Genetics 2015;16:275-84.

9. 16.Slater HR, Bailey DK,Ren $\mathrm{H}$ et al. High-resolution identification of chromosomal abnormalities using oligonucleotide arrays containing 116,204 SNPs . Am J Hum Genet 2005;77:709-26.

10. 17. Go, A. T. J. I.; Van Vugt, J. M. G.; Oudejans, C. B. M. (2010). "Non-invasive aneuploidy detection using free fetal DNA and RNA in maternal plasma: Recent progress and future possibilities". Human Reproduction Update 17 (3):372-82.

11. 18. Consent and Confidentiality in Medical Genetics Practice (April 2006) prepared by Joint Committee of Medical Genetics.

www.bshg.org.uk/documents/official_docs. 